\title{
Vitamin A and beta-carotene supplementation in horses on different forage systems
}

\author{
KM Greiwe-Crandell, DS Kronfeld, D Sklan \\ Virginia Polytechnic Institute and State University, Middleburg Agricultural Research \\ and Extension Center, Middleburg, VA 22117, USA
}

Forages, such as pastures and hays, often require supplementation to be utilized efficiently, especially as the nutritional value of pastures declines during fall and winter. A common supplement is vitamin A which influences many functions, notably reproduction and growth in the horse. Its dietary precursor, beta-carotene progressively deteriorates in pastures after they stop growing during the fall and winter, as well as in hays and other conserved feeds, so additional sources of vitamin A are often required for grazing or stabled herbivores.

Forty-five Thoroughbred mares were divided into 3 groups and kept on different forage systems for 30 months. The first forage system was a dry lot where mares were fed grass hay and a concentrate made without vitamin $A$ added $(\mathrm{HC})$. The second and third systems were bluegrass/clover pastures supplemented with alfalfa/grass hay during the winter $(\mathrm{PH})$ where one of the groups was also fed the vitamin $\mathrm{A}$ free concentrate $(\mathrm{PHC})$. The mares were on these diets for at least 8 months, during which vitamin $A$ status was depleted as assessed by serum retinol concentration and a relative doe response (RDR) test (GreiweCrandell et al, 1993, 13th ENPS Proc, 1-2), before any vitamin $A$ supplementation was started. In the repletion phase, each group of 15 mares was divided into 3 subgroups : 5 mares were supplemented with vitamin $A$ palmitate at twice the NRC requirement (A) ; 5 mares were given beta-carotene at the equivalent of twice the NRC requirement of vitamin $A(B)$; and the last 5 mares were given a placebo (C). Supplements were given 2 times per week orally and individually. Every 2 months vitamin A status was assessed by RDR test and serum retinol concentration. The foals born during the experimental period were subjected to a RDR test within the first 24 hours.

Over the 22 month period, means of serum retinol concentration were $18.5,20.4$ and $20.3 \mathrm{ug} / \mathrm{dl}$ (SE $0.33 \mathrm{ug} / \mathrm{dl}$ ) in control, betacarotene and vitamin A supplemented mares, respectively $(P<0.05)$. Corresponding RDR values were 15.7, 15.0 and $10.7 \%$ (SE $0.64 \%)(P<0.05)$. We conclude that supplementation with vitamin $A$ palmitate was more effective than beta-carotene in improving vitamin $A$ status. 